\title{
Characteristics and conflicts of interests of public speakers at the Psychopharmacologic Drug and Advisory Committee meetings regarding psychiatric drugs
}

\section{Will Roberts (1), Samuel Jellison (1), Cole Wayant (ㄷ), Matt Vassar}

10.1136/bmjebm-2019-111299

Research, Oklahoma State University Center for Health Sciences, Tulsa, Oklahoma, USA

Correspondence to: Will Roberts, Research, Oklahoma State University Center for Health Sciences, Tulsa, OK 74107, USA; Will. roberts10@okstate.edu

\section{Abstract}

The Psychopharmacologic Drug Advisory Committee (PDAC) is one of 33 advisory committees of the Food and Drug Administration (FDA). During committee meetings, an open public hearing takes place where speakers provide testimonies about the drug in question and are asked, not required, to disclose any conflicts of interests (COIs) before speaking. These speakers may present with COIs which include, but are not limited to, reimbursement for travel and lodging by the pharmaceutical company to attend the meeting; previous or current payments for consulting from the pharmaceutical company and compensation as a paid investigator in previously conducted clinical trials for the drug under review. Our study aimed to investigate the characteristics and COIs of public speakers at PDAC meetings of the FDA. We evaluated 145 public speakers at FDA committee meetings over a 10-year period. We found a total of 52 public speakers disclosed a COI with travel and lodging being the most prominent. Among these speakers, $82.4 \%$ provided a positive testimony regarding the psychiatric drug in question. Speakers who had the condition in question were not more likely to provide a positive statement than those who did not. Our results showed that disclosing a COI was associated with increased odds of public speakers providing a favourable testimony for the recommendation of psychiatric drugs. The implications of these findings are concerning since COIs have the potential to skew public speaker's testimonies and persuade committee members to recommend a drug through emotionally charged tactics.

\section{Introduction}

The Psychopharmacologic Drug Advisory Committee (PDAC) is one of 33 advisory committees of the Food and Drug Administration (FDA) responsible for reviewing safety and efficacy data for human and investigational psychiatric drug products and making recommendations to the Commissioner of Food and Drugs for or against approval. ${ }^{1}$ During committee meetings, an open public hearing takes place where speakers provide testimonies regarding the drug in question. Prior to providing their testimony, speakers are asked,
Key messages

What is already known about this subject?

- The Psychopharmacologic Drug Advisory Committee is one of 33 advisory committees of the Food and Drug Administration responsible for reviewing safety and efficacy data for human and investigational psychiatric drug products.

- During committee meetings, an open public hearing takes place where speakers provide testimonies regarding the drug in question.

- Initial evidence has demonstrated a relationship between conflicts of interests (COIs) of these public speakers and their likelihood for providing a positive testimony.

What are the new findings?

- Our results showed that disclosing a COI was associated with increased odds of public speakers providing a favourable testimony for the recommendation of psychiatric drugs.

- At these meetings, more than onethird of the 145 public speakers disclosed a COI and more than threefourths of these speakers provided a positive testimony with travel and lodging being the most prominent.

- Additionally, we found that 24 out of the 145 public speakers did not mention their $\mathrm{COI}$, and among these speakers, nearly half of them provided a positive testimony.

How might it impact clinical practice in the foreseeable future?

- The implications of these findings are concerning since COls have the potential to skew public speaker's testimonies at these meetings and persuade committee members to look beyond the evidence and approve a drug through the acquisition of nonevidence-based information. 
not required, to disclose any conflicts of interest (COIs). These COIs include, but are not limited to, reimbursement for travel and lodging by the pharmaceutical company to attend the meeting; previous or current payments for consulting from the pharmaceutical company and compensation as a paid investigator in previously conducted clinical trials for the drug under review. ${ }^{2}$ These COIs have the potential to bias the testimony of public speakers at PDAC meetings and encourage the committee to recommend the approval of the drug. ${ }^{34}$

Ideally, drug approval decisions should be objective, using results from well-designed, well-executed and adequately powered randomised trials as a basis for decision making. However, public speakers may be carefully selected by pharmaceutical companies and trained to use emotional tactics that have the potential to persuade committee members to look beyond the evidence and recommend approval of a drug. ${ }^{5}$ Initial evidence has demonstrated a relationship between COIs of these public speakers and their likelihood for providing a positive testimony; ${ }^{267}$ however, little is known regarding their effect in psychiatry. Here, we extend the work of previous studies by evaluating the characteristics and COIs of public speakers at PDAC meetings regarding psychiatric drugs.

\section{Methods}

This study used publicly accessible data of FDA transcripts and, thus, it did not meet the regulatory definition of human subjects research per the United States Code of Federal Regulations and did not require the oversight of an institutional review board approval. We identified all PDAC meetings on the FDA website from April 2009 to March $2019(n=18)$ and reviewed the published transcripts of these meetings. ${ }^{1}$ We excluded meetings that had no public speakers $(n=1)$, meetings that had lost a significant amount of information due to poor transcription $(n=1)$ and meetings that had inaccessible transcripts on the FDA website $(n=2)$. We have no reason to believe that public speaker testimonies from these meetings were substantially different than those included in our sample.

\section{Data extraction}

Two authors (WR and SJ) used a pilot-tested Google form to perform blinded, independent data extraction and recorded whether the speakers reported having the condition in question, were taking or had previously taken the drug in question or disclosed a COI, and if yes, the nature of the COI. We created the following speaker categories: patient advocate, friend or relative of the patient, general public (ie, unrelated to a patient or organisation with industry ties), industry representative, medical organisation representative (eg, medical school or professional society), non-profit and patient. The two authors classified each testimony as positive, negative or neutral concerning drug approval. Positive testimonies included statements such as, 'There should be a yes vote on this drug.' Neutral testimonies included statements such as, 'When considering this application, I urge the committee to not abandon the patient community.' Negative testimonies included statements such as, 'We cannot urge you to support the approval of this drug.' We classified all statements by the speaker's final suggestions for or against the approval of a drug, and thus we did not have any situations where there was a combination of positive, negative or neutral testimonies. All statements were reviewed and categorised in a dual, blinded and independent fashion. Any discrepancies were resolved by consensus from the two authors (WR and SJ) after completion of the review. A third-party investigator (CW) was present if necessary during the discrepancy resolution but ultimately was not needed.

\section{Data analyses}

We performed an ordered logistic regression using the statement about the drug (positive, neutral or negative) as the dependent variable. The initial independent variables included conflict of interest, whether the public speaker was taking or had previously taken the drug and whether the public speaker had the condition the drug was said to treat. After running descriptive statistics, we found that only 12 public speakers were taking or had previously taken the drug. Because of the small number of cases of this variable, we made the decision to exclude it from the regression model. All responses were used including those from people who reviewed more than one drug at different meetings. All analyses were conducted using Stata 15.1.

\section{Results}

We extracted 145 public speakers from 14 PDAC meeting transcripts with a mean of $10.4(\mathrm{SD}=5.89)$ speakers per meeting. Table 1 lists the number of speakers, the drug names and the respective drug companies associated with each PDAC meeting. Before resolving discrepancies, interrater reliability was within acceptable ranges (Gwet's $\mathrm{AC} 1=0.86,95 \% \mathrm{CI} 0.83$ to 0.89). The most common speakers at PDAC meetings were those from the general public (36/145, 24.8\%), non-profit $(29 / 145,20 \%)$, patient $(25 / 145,17.2 \%)$, industry representative $(20 / 145,13.8 \%)$, medical organisation representative $(18 / 145,12.4 \%)$, friend or relative of the patient $(15 / 145,10.3 \%)$ and patient advocate $(2 / 145,<1 \%)$.

Out of the 145 speakers at PDAC meetings, 71 (49\%) made a positive statement about the drug, 34 (23.4\%) made a negative statement and $40(27.6 \%)$ made a neutral statement. Regarding COI status, 121/145 (83.4\%) speakers included a COI disclosure statement and 52/145 (35.9\%) speakers disclosed a COI.

Most closures were related to travel expenses (29/52, 55.8\%) or as paid consultants by the pharmaceutical company (7/52, 13.5\%). Among the 52 speakers who disclosed a COI, 42 (82.4\%) of them provided a positive statement. Among the speakers who either did not reveal a COI or did not mention a COI, 30/93 (32.3\%) provided a positive statement. Speakers who had previously or were currently taking the drug in question provided a positive statement in 11/12 (91.7\%) instances and speakers who had the condition in question provided a positive statement in 16/29 $(55.2 \%)$ instances. Speaker characteristics and their types of COI can be located in table 2 .

Our ordered logistic regression model found that speakers who disclosed a COI were significantly more likely to give a positive testimony than those who did not $(\mathrm{OR}=3.0,95 \% \mathrm{CI} 2.02$ to 4.45 , $\mathrm{p}<0.001)$. Speakers who had the condition in question were not more likely to provide a positive testimony than those who did not (OR=1.39, 95\% CI 0.6 to $3.18, \mathrm{p}=0.44)$.

\section{Discussion}

We investigated whether COIs were associated with public speakers providing favourable testimonies at PDAC meetings. Our results showed that disclosing a COI was associated with increased odds of public speakers providing a favourable testimony for the recommendation of psychiatric drugs. At these meetings, more than one-third of the 145 public speakers disclosed a COI and more than three-fourths of these speakers provided a positive testimony with travel and lodging being the most prominent. Speakers who had the condition in question were not more likely to provide a positive statement than those who did not. Additionally, we found 


\begin{tabular}{|c|c|c|c|}
\hline Drug name & Drug company & $\begin{array}{l}\text { \# of } \\
\text { speakers }\end{array}$ & $\begin{array}{l}\text { \# of speakers } \\
\text { with COIs }\end{array}$ \\
\hline Serdolect (sertindole) & Lundbeck & 2 & 0 \\
\hline Seroquel XR (quetiapine fumarate) & Astra Zeneca Pharmaceuticals & 14 & 1 \\
\hline Geodon, Seroquel, Zyprexa & $\begin{array}{l}\text { Pfizer Inc., Astra Zeneca Pharmaceuticals, Eli Lilly and } \\
\text { Company }\end{array}$ & 23 & 1 \\
\hline Adasuve (loxapine) & Alexza Pharmaceuticals & 2 & 2 \\
\hline $\begin{array}{l}\text { Probuphine (buprenorphine hydrochloride and ethylene vinyl } \\
\text { acetate) }\end{array}$ & Titan Pharmaceuticals Inc. & 11 & 6 \\
\hline Chantix (varenicline tartrate) & Pfizer Inc & 7 & 0 \\
\hline Gepirone hydrochloride XR & Fabre-Kramer Pharmaceuticals Inc. & 7 & 2 \\
\hline $\begin{array}{l}\text { Probuphine (buprenorphine hydrochloride and ethylene vinyl } \\
\text { acetate) }\end{array}$ & Titan Pharmaceuticals Inc. & 18 & 8 \\
\hline Vortioxetine & Takeda Development Center Americas, Inc. & 6 & 5 \\
\hline Nuplazid (pimavanserin) & Acadia Pharmaceuticals Inc. & 15 & 8 \\
\hline Lofexidine hydrochloride & US WorldMeds, Inc. & 6 & 2 \\
\hline Buprenorphine and samidorphan & Alkermes & 13 & 5 \\
\hline Brexanolone & Sage Therapeutics & 14 & 9 \\
\hline Esketamine $28 \mathrm{mg}$ single-use nasal spray device & Janssen Pharmaceuticals, Inc. & 7 & 3 \\
\hline
\end{tabular}

COI, conflicts of interest; PDAC, Psychopharmacologic Drug Advisory Committee.

that 24 out of the 145 public speakers did not mention their COI, and among these speakers, nearly half of them provided a positive testimony. The implications of these findings are concerning since COIs have the potential to skew public speaker's testimonies at these meetings and persuade committee members to look beyond the evidence and approve a drug through the acquisition of nonevidence-based information.

Our primary finding-disclosing a COI was associated with increased odds of public speakers giving a positive testimonyaligns with previously published research from three previous investigations. Abola and Prasad $^{7}$ found that 31 out of 103 public speakers reported financial COI at Oncologic Drug Advisory Committee (ODAC) meetings and all of these associated speakers provided positive remarks regarding the drug in question. The authors stated that committee members should keep these financial associations in mind when listening to the speaker's testimonies

\begin{tabular}{ll}
\hline $\begin{array}{l}\text { Table } 2 \text { Number of speakers ( } \mathrm{n}=145) \text {, their characteristics, and types } \\
\text { of COI }\end{array}$ \\
\hline $\begin{array}{l}\text { Speakers who disclosed a non-financial COI } \\
\text { Speakers with condition in question }\end{array}$ & $29(20 \%)$ \\
\hline $\begin{array}{l}\text { Speakers taking drug in question } \\
\text { Speakers who disclosed a financial COI }\end{array}$ & $12(8.3 \%)$ \\
\hline Travel and lodging & $29(55.8 \%)$ \\
\hline Paid consultant for pharmaceutical company & $7(13.5 \%)$ \\
\hline $\begin{array}{l}\text { Organisation represented receives funding from } \\
\text { pharmaceutical company }\end{array}$ & $6(11.5 \%)$ \\
\hline Paid investigator in clinical trials & $5(9.6 \%)$ \\
\hline Participated in drug trials+travel expenses & $3(5.8 \%)$ \\
\hline Owns stock in the company & $1(<1 \%)$ \\
\hline Disclosed COI but did not specify & $1(<1 \%)$ \\
\hline Speaker's position on drug approval & $71(49 \%)$ \\
\hline Positive & $34(23.4 \%)$ \\
\hline Negative & $40(27.6 \%)$ \\
\hline Neutral
\end{tabular}

COI, conflicts of interest. during open public hearings due to the possible effects that these COIs may have on the speaker's testimonies. Additionally, McCoy et $a l^{2}$ found that almost 25\% of speakers at Anesthetic and Analgesic Drug Products Advisory Committee (AADPAC) meetings contained COIs but nearly 20\% of these speakers did not properly disclose their conflicts. In addition, the authors found that these COIs significantly increased the speaker's chances of providing support for approval of a drug and concluded that sponsorrelated bias may be in effect at these meetings. Finally, Arthur et $a l^{6}$ found that 126 out of 129 speakers who disclosed a COI at Peripheral and Central Nervous System Drug Advisory Committee meetings gave a positive testimony about the drug in question. These authors concluded that given the influence that industryrelated COIs may have on the nature of public speaker's testimonies at these meetings, further precautions should be implemented to prevent the future persuasion of committee members endorsing a drug like eteplirsen, whose approval may have been influenced by emotionally charged tactics. ${ }^{5}$ Thus, our study's findings provide additional support to the belief that COIs may influence the nature of public speaker's testimonies at FDA meetings. Our findings do not provide support that speakers who had the disease for which the drug was indicated or who took the drug were more likely to recommend the drug. These circumstances have been described as non-financial COIs and have been a source of debate in the published literature. Some authors argue that financial COIs should be the primary consideration, as financial ties have been extensively studied and are known to contribute to bias. ${ }^{8-12}$ Other authors warn that non-financial COIs may be problematic and that medical bias could possibly have an effect on the assessment of evidence by scientists or others. ${ }^{13}$ Currently, the FDA only considers COIs that are financial in nature to be necessary for disclosure. $^{14}$

We recommend pharmaceutical companies not be allowed to handpick the patients they want to speak during open public hearings, but rather random video diaries from patients involved in the drug's clinical trial phases be played at these hearings instead to promote transparency and validity regarding the approval process, as suggested by Hayes and Prasad. ${ }^{15}$ For example, patients involved in these trials may be preselected to 
record video updates regarding their experience and viewpoint of the drug throughout the clinical trial phase and a random selection of these video diaries be played for the panel during committee meetings to provide representative patient testimony. This implemented process may help ensure non-emotionally charged testimonies are presented to the committee and potentially reduce the risk of bias regarding the approval of psychiatric drugs. Additionally, we acknowledge that public speakers are not the only parties who present with COIs at FDA advisory meetings, and these COIs may also affect committee recommendations regarding drug approval; hence, we decided to briefly discuss them as follows.

Lammers et $a l^{16}$ reviewed 35 ODAC meetings between 2011 and 2015 and found that 35 out of 38 experts (US healthcare professional with an MD degree) who spoke at these meetings had received industry payments with a mean income of \$39 316. In addition, this study found a strong correlation among these expert's payments and their degree of academic success. Thus, the higher number of publications or citations ascribed to these experts, the greater the amount of industry payments they received. A 2006 study investigated the voting patterns of advisory committee members from 221 meetings held by 16 different committees over a 4-year period. This study found that $73 \%$ of meetings contained at least one committee member with a financial obligation and these financial associations exceeded $\$ 100000$ in select cases. ${ }^{17}$ Graham et al ${ }^{18}$ sought to examine the relationship between industry and patient-consumer representatives serving on the FDA drug advisory committees by investigating all 167 FDA advisory committee meetings between 2009 and 2012. This study found COIs to be present in onethird of these meetings with half of the COIs to be valued at $\$ 50000$ or more. The authors concluded with recommendations to the FDA to change the way they evaluate COIs for patient and consumer representatives; specifically, a revision to their guidelines was suggested regarding the requirement of advisory committee members to list their financial relationships between industry and organisations (form 3410). Thus, evidence from the body of literature on COIs and FDA committees coupled with results from the present study support the notion that the FDA's drug approval process may lack transparency and is subject to possible bias created by financial associations between pharmaceutical companies and public speakers, expert speakers and advisory committee members.

We recognise that disclosure of COIs alone is not sufficient to mitigate bias. We agree with the recommendations by McCoy and Emmanuel ${ }^{19}$ who suggest that, in addition to stronger disclosure rules for public speakers, additional procedures should be considered for implementation by the FDA regarding COIs, namely stricter management of COIs or prohibition. Management practices might include limiting the number of speakers who have COIs, whereas prohibition would eliminate public speakers with COIs altogether. Whether one or more of these procedures are employed, we believe that these alternatives would help the FDA accomplish its mission for "protecting the public health by assuring the safety, efficacy and security of human and veterinary drugs, biological products, medical devices.... ${ }^{20}$

This study has strengths and limitations. Key strengths include the fact that our methodology was modelled after prior studies, all of which have been peer-reviewed in distinct areas of medicine. ${ }^{26}$ Additionally, our pilot-tested, double-blinded data extraction helps mitigate bias and adds to the validity of our results. Our study has limitations. This study was cross-sectional, which may restrict its generalisability. Even though we extensively searched throughout the FDA's website, we were unable to find two transcripts from PDAC meetings, which may have contained public speakers that could have altered our results. In addition, we were forced to discard another meeting due to poor transcription quality during the session.

\section{Conclusion}

We aimed to investigate the characteristics and COIs of public speakers at PDAC meetings. We evaluated 145 public speakers at these meetings over a 10 -year period. Our results showed that disclosing a COI was associated with increased odds of public speakers providing a favourable testimony for the recommendation of psychiatric drugs. At these meetings, more than onethird of the 145 public speakers disclosed a COI and more than three-fourths of these speakers gave a positive testimony with travel and lodging being the most prominent. Speakers who had the condition in question were not more likely to provide a positive statement than those who did not. Additionally, we found $16.5 \%$ of speakers at PDAC meetings did not mention their COI. The implications of these findings are concerning since COIs have the potential to skew public speaker's testimonies and persuade committee members to recommend a drug through emotionally charged tactics. We recommend pharmaceutical companies not be allowed to handpick the patients they want to speak during open public hearings, but rather random video diaries from patients involved in the drug's clinical trial phases be played at these hearings instead to promote transparency and validity regarding the approval process. Furthermore, we recommend additional procedures be considered for implementation by the FDA regarding COIs, namely stricter management of COIs or prohibition.

\section{Twitter Will Roberts @willrobsmed and Cole Wayant @ ColeWayant_OK}

Contributors All authors have made substantial contributions to all of the following: (1) the conception and design of the study, or acquisition of data, or analysis and interpretation of data, (2) drafting the article or revising it critically for important intellectual content, (3) final approval of the version to be submitted.

Funding The authors have not declared a specific grant for this research from any funding agency in the public, commercial or not-for-profit sectors.

\section{Competing interests None declared.}

Patient consent for publication Not required.

Ethics approval This study used publicly accessible data of FDA transcripts and, thus, it did not meet the regulatory definition of human subjects research per the United States Code of Federal Regulations and did not require the oversight of an institutional review board approval.

Provenance and peer review Not commissioned; externally peer reviewed.

Data availability statement Data are available on reasonable request. This study used publicly accessible data from the FDA's website and, thus, it did not qualify for institutional review board approval.

\section{ORCID iDs}

Will Roberts http://orcid.org/0000-0002-9475-975X 
Samuel Jellison http://orcid.org/0000-0001-9014-2165

Cole Wayant http://orcid.org/0000-0001-8829-8179

\section{References}

1 Center for Drug Evaluation, Research. Psychopharmacologic drugs Advisory Committee. U.S. food and drug administration, 2018. Available: http://www.fda.gov/advisory-committees/human-drug-advisorycommittees/psychopharmacologic-drugs-advisory-committee [Accessed 21 Oct 2019].

2 McCoy MS, Pagán 0, Donohoe G, et al. Conflicts of interest of public speakers at meetings of the anesthetic and analgesic drug products Advisory Committee. JAMA Intern Med 2018;178:996.

3 Pulliam S, Mullins B. How the FDA approved a \$300,000-a-year drug its own experts didn't believe worked. WSJ Online, 2017. Available: https:// www.wsj.com/articles/how-the-fda-approved-a-300-000-a-year-drug-itsown-experts-didnt-believe-worked-1495116544 [Accessed 27 Nov 2019].

4 Segal JZ. The rhetoric of female sexual dysfunction: faux feminism and the FDA. Can Med Assoc J 2015;187:915-6.

5 Kesselheim AS, Avorn J. Approving a problematic muscular dystrophy drug: implications for FDA policy. JAMA 2016;316:2357-8.

6 Arthur W, Austin J, Wayant C, et al. Association of conflicts of interest for public speakers for the peripheral and central nervous system drugs Advisory Committee of the US food and drug administration with their statements. JAMA Neurol 2019;76:368-9.

7 Abola MV, Prasad V. Characteristics and conflicts of public speakers at meetings of the oncologic drugs Advisory Committee to the US food and drug administration. JAMA Intern Med 2016;176:389-91.

8 Lundh A, Sismondo S, Lexchin J, et al. Industry sponsorship and research outcome. Cochrane Database Syst Rev 2012;12:MR000033.

9 Bero L, Anglemyer A, Vesterinen H, et al. The relationship between study sponsorship, risks of bias, and research outcomes in atrazine exposure studies conducted in non-human animals: systematic review and metaanalysis. Environ Int 2016;92-93:597-604.
10 Anglemyer AT, Krauth D, Bero L. Industry sponsorship and publication bias among animal studies evaluating the effects of statins on atherosclerosis and bone outcomes: a meta-analysis. BMC Med Res Methodol 2015;15:12.

11 Vartanian LR, Schwartz MB, Brownell KD. Effects of soft drink consumption on nutrition and health: a systematic review and metaanalysis. Am J Public Health 2007;97:667-75.

12 Barnes DE, Bero LA. Why review articles on the health effects of passive smoking reach different conclusions. JAMA 1998;279:1566-70.

13 Shaw DM. A piece of my mind. beyond conflicts of interest: disclosing medical biases. JAMA 2014;312:697-8.

14 Food PUS. Financial conflict-of-interest disclosure and voting patterns at FDA advisory committee meetings. Available: https://www.fda.gov/ files/advisory\%20committees/published/Financial-Conflict-Of-InterestDisclosure-And-Voting-Patterns-At-FDA-Advisory-Committee-Meetings. pdf

15 Hayes MJ, Prasad V. Financial conflicts of interest at FDA drug Advisory Committee meetings. Hastings Cent Rep 2018;48:10-13.

16 Lammers A, Edmiston J, Kaestner V, et al. Financial conflict of interest and academic influence among experts speaking on behalf of the pharmaceutical industry at the US food and drug administration's oncologic drugs Advisory Committee meetings. Mayo Clin Proc 2017;92:1164-6.

17 Lurie P, Almeida CM, Stine N, et al. Financial conflict of interest disclosure and voting patterns at food and drug administration drug Advisory Committee meetings. JAMA 2006;295:1921-8.

18 Graham SS, Card DJ, Ahn S, et al. Conflicts of interest among patient and consumer representatives to U.S. food and drug administration drug Advisory committees. Ann Intern Med 2016;165:606-7.

19 McCoy MS, Emanuel EJ. Health policy: addressing conflicts of interest of public speakers at Advisory Committee meetings. Nat Rev Clin Oncol 2016;13:267-8.

20 FDA. Mission possible: how FDA can move at the speed of science, 2009. Available: https://www.fda.gov/media/93524/download [Accessed 26 Nov 2019]. 